Andamios del psicoanálisis: lenguaje vivo y lenguage muerto en las teorías psicoanalíticas. Ricardo Rodulfo

Buenos Aires, Argentina: Paidós, 2013, 288 págs.

\title{
Andaimes da psicanálise: desconstruções a partir da proposta de Ricardo Rodulfo
}

Psychoanalysis scaffolding: deconstruction based on

Sandra Diambolakdjian Torossian*1

Ricardo Rodulfo, psicanalista argentino contemporâneo, mais conhecido no Brasil pelas suas obras traduzidas: O brincar e o significante: um estudo psicanalítico sobre a constituição precoce (1990), e Desenhos fora do papel: da carícia à leitura escrita na criança (2004), vem realizando um trabalho que ele denomina desconstrução da psicanálise tradicional. Um dos últimos textos dedicados a esse fim é o livro Andamios del Psicoanálisis: lenguaje vivo y lenguaje muerto en las teorías psicoanalíticas (2013), ainda sem tradução para o português.

${ }^{* 1}$ Universidade Federal do Rio Grande do Sul (Porto Alegre, RS, Brasil). 
A desconstrução formulada por Rodulfo sustenta-se na proposta de Jacques Derrida. Numa crítica àquela psicanálise que anda em "linhas retas", Rodulfo toma a psicanálise em todas as suas vertentes e vértices, como um sistema teórico no qual os vários autores e as várias "linhas" podem estar em conexão. Ao grifar a posição do autor perante o texto destacamos uma leitura sustentada no trânsito entre diversos teóricos da psicanálise. É esse um ponto no qual muitos psicanalistas justificariam a necessidade de filiação a uma "linha". Rodulfo, no entanto, afirma a necessidade da desconstrução da hierarquia opositiva. No trânsito entre textos o autor olha também para o "prazo de validade" dos conceitos ao perguntar se algumas das propostas conceituais da psicanálise não teriam sua validade caducada cedendo lugar a outras em função do espaço-tempo na qual foram concebidas.

Nessa direção, Rodulfo recorre a Foucault e Deleuze para movimentar o campo, incorporando as críticas e revendo o corpus da psicanálise sem produzir ali fendas intransponíveis que derivariam numa antipsicanálise. Dividido em três partes, além do prefácio, o livro realiza um percurso desconstrutivo em 17 capítulos.

O tema do pai, afirma Rodulfo, nem sempre foi produtivo para a psicanálise. Convidando Deleuze para essa conversa, retoma a crítica à centralidade que o tema da paternidade assume na política da psicanálise. Rodulfo sustenta que ao reivindicar o lugar paterno, Freud deixou de reconhecer um trabalho compartilhado com outros profissionais e com os pacientes. $\mathrm{O}$ autor pergunta se seria possível desprivatizar a psicanálise devolvendo-a à circulação na vida cultural.

Através desse questionamento abre-se a passagem para a primeira parte do livro, dedicada a trabalhar com a différance no texto de alguns temas psicanalíticos e nos pressupostos científicos que os sustentam. É o caso de voltar a olhar - diferenciando e diferindo - temas como o complexo de Édipo, o incesto, a especularidade e o brincar, ressaltando a passagem do modelo da física mecânica, no qual Freud sustentou boa parte das suas contribuições, para o modelo da física quântica. Nessa torção novos modos de olhar o mundo se produzem, assim como podem ser produzidas variações nos modos de olhar da psicanálise.

A segunda parte do livro, apresentada em oito capítulos, apresenta variações produzidas nos modos de subjetivação da infância e adolescência e suas consequências na clínica com crianças e jovens. Além disso, Rodulfo retoma aqui um trabalho que vem desenvolvendo desde seus primeiros textos em relação à função do brincar na constituição subjetiva. Sempre partindo de interrogações produzidas na clínica, retoma a elaboração das suas teses sobre 


\section{RESENHAS BIBLIOGRÁFICAS}

o brincar, nas quais Winnicott é um dos seus grandes interlocutores. Na psicanálise com crianças, sustenta, há dois tempos: antes e depois de Winnicott. O antes e o depois não se situam numa lógica da cronologia, mas a partir do que se entende ser uma criança e do efeito que as crianças produziram na psicanálise.

No tempo antes a psicanálise é introduzida na criança; já no tempo depois a criança é introduzida no interior da psicanálise. Aqui vale uma analogia que o autor vem utilizando em alguns tempos de sua escrita: assim como uma casa não fica a mesma depois de passarem por ela as crianças, não é possível que a psicanálise fique sem se modificar ao brincarem nela as crianças.

Após o trabalho desconstrutivo em relação à temática da subjetivação e da clínica com crianças e adolescentes, o último capítulo é dedicado à discussão psicopatológica. No texto denominado "Sonatina", trabalham-se os temas da normalidade, loucura e saúde. Ressaltando a resistência recíproca entre loucura e normalidade, a saúde é colocada como terceiro possível.

Várias são as temáticas presentes nesse livro, discutidas à luz da desconstrução. Fios que vêm se desdobrando nos seus textos há alguns anos são retomados aqui para mais um giro analítico na perspectiva aberta por Derrida. A suspensão de alguns temas, costumeiramente colocadas no centro da teoria psicanalítica, como o complexo de Édipo, é uma das vias da desconstrução que o autor propõe em "Psicanálise sem centro". É nessa trilha que destacamos o terceiro capítulo provocativamente intitulado "La prescripción del incesto".

Nesse capítulo, Rodulfo convida Foucault a ingressar no texto psicanalítico com suas ideias mais críticas em relação ao "Édipo". Alertando sobre a necessidade de articular a experiência clínica com a cultura na qual ela tem lugar, Rodulfo se propõe a desconstruir a noção segundo a qual entende-se que "se há cultura é pela proibição do incesto". Um dos modos de realizar esse trabalho é substituir o ponto final afirmativo por uma interrogação. $\mathrm{O}$ diálogo com Foucault permite discutir o caráter negativo que se tem atribuído ao incesto quando ele é lido somente como ação de desalojar, recalcar, reprimir e barrar. Foucault defende que a proibição apresenta também um caráter positivo quando oferece caminhos e modelos, não se limitando meramente ao "não". Devemos salientar aqui que muitas dessas produções devem-se mais às leituras que se tem realizado dos textos clássicos da psicanálise sobre a proibição do incesto do que necessariamente às formulações específicas de Freud ou Lacan, por exemplo.

A partir dessa concepção de negatividade e positividade da proibição do incesto, Rodulfo destaca o caráter de regulação que a proibição introduz. 
Isso permite-lhe afirmar que a cultura proíbe parte do incestuoso, mas também promove algumas das suas manifestações.

Várias são as questões abertas e desdobradas por esse livro. Contribuições sempre geradas a partir da experiência clínica. Essa, parece-nos, é uma direção necessária à investigação psicanalítica. A perspectiva desconstrutiva nos obriga a colocar em questão nossas certezas, especialmente quando essas estão ancoradas em fundamentos dogmáticos que podem passar despercebidos. Trata-se de uma leitura que desacomoda, mas que pode fazer parte de uma produção legitimadora de ancoragens abrindo, também, espaço ao novo.

Citação/Citation: Torossian, S. D. (2018, setembro). Andaimes da psicanálise: desconstruções a partir da proposta de Ricardo Rodulfo. Resenha do livro Andamios del Psicoanálisis: lenguaje vivo y lenguaje muerto en las teorías psicoanalíticas. Revista Latinoamericana de Psicopatologia Fundamental, 21(3), 665-668. http://dx.doi.org/10.1590/1415-4714.2018v$21 \mathrm{n} 3 \mathrm{p} 665.14$.

Editores do artigo/Editors: Profa. Dra. Sonia Leite e Profa. Dra. Marta Regina de Leão D’Agord

Recebido/Received: 15.8.2018 / 8.15.2018 Aceito/Accepted: 25.8.2018 / 8.25.2018

Copyright: (C) 2009 Associação Universitária de Pesquisa em Psicopatologia Fundamental/ University Association for Research in Fundamental Psychopathology. Este é um artigo de livre acesso, que permite uso irrestrito, distribuição e reprodução em qualquer meio, desde que o autor e a fonte sejam citados / This is an open-access article, which permits unrestricted use, distribution, and reproduction in any medium, provided the original authors and sources are credited.

\section{SAndra DJambolakdjian Torossian}

Doutora em Psicologia pela Universidade Federal do Rio Grande do Sul - UFRGS (Porto Alegre, RS, Br); Professora do Departamento de Psicanálise e Psicopatologia e do PPG em Psicanálise: Clínica e Cultura do Instituto de Psicologia da mesma Universidade.

Rua Mariante, 650/302 - Rio Branco

90430-180 Porto Alegre, RS, Br.

djambo.sandra@gmail.com

This is an open-access article, which permits unrestricted use, distribution, and reproduction in any medium for non-commercial purposes provided the original authors and sources are credited. 